\title{
Application of Three-Dimensional Visualization Technology in Project Management of Offshore Platform Engineering Construction
}

\author{
Jianyuan Yang, Songlin Xia, Jie Shang, Shaofang Li, Zhongde Zhang \\ Tianjin Branch of CNOOC (China) Co., Ltd., Tianjin, China \\ Email: yangjy3@cnooc.com.cn
}

How to cite this paper: Yang, J.Y., Xia, S.L., Shang, J., Li, S.F. and Zhang, Z.D. (2019) Application of Three-Dimensional Visualization Technology in Project Management of Offshore Platform Engineering Construction. Engineering, 11, 727-734.

https://doi.org/10.4236/eng.2019.1111047

Received: September 29, 2019

Accepted: October 26, 2019

Published: October 29, 2019

Copyright () 2019 by author(s) and Scientific Research Publishing Inc. This work is licensed under the Creative Commons Attribution International License (CC BY 4.0).

http://creativecommons.org/licenses/by/4.0/

\begin{abstract}
Three-dimensional visualization technology converts engineering design drawings and data into graphics or images, realizes virtual reality perception of simulated users in future construction scene, enhances the interaction between project management and technical personnel and engineering construction achievement, and provides intuitive, flexible and strong realistic experience for project management. It can effectively improve the level of project communication, and assist the needs of project construction planning management, training, exhibition, etc. As a tool to help improve project management skills, it has good application effect and prospects.
\end{abstract}

\section{Keywords}

Three-Dimensional Visualization, Virtual Reality, Engineering Construction, Project Management

\section{Introduction}

Visualization requirements for engineering construction projects have existed all the time. For example, Li Jie in the Northern Song Dynasty drew a large number of engineering drawings in the "Create a French style". In the book, the so-called site drawings, regular drawings and side drawings are similar to the plane, elevation and section drawings of modern buildings. These essentials can be understood as an initial demand of ancient human for visualization of engineering construction [1]-[10].

In fact, as long as it is technically and economically possible, visualization of construction projects is often the most urgent requirement. Because of the inherent uniqueness, non-repeatability and irreversibility of construction projects, 
project decision-makers, project managers and engineering technicians all hope to see how the projects are built, what they are after completion and whether they meet their own requirements before the implementation of the project, whenever possible, in order to make the most appropriate decisions, decision-making and implementation plan.

Before the maturity of computer technology, people showed the buildings to be built by hand drawing effect maps, perspective drawings and so on. In modern times, with the rapid development of computer image technology, it is easier to visualize construction projects and more and more ways of expression. Therefore, more and more visualization requirements for construction projects are required. Especially, the application of three-dimensional visualization technology in construction project management is becoming more and more mature.

\section{Technological Theory}

Three-dimensional visualization is a comprehensive technology which integrates data processing, image display, human-computer interaction and other functions from the perspective of computer science. It has been widely used in architecture, geography, ocean, surveying and mapping and other disciplines. The abstract and boring data and text can be processed into intuitive graphics and animation, and the real-time changes of light, color, visual angle and other factors can be used so that users can not only intuitively observe the appearance of the simulated object, but also go deep into its internal structure, and even view the physical scene, which is difficult to observe the details, but also with the design.

Virtual reality (VR) is an application form of the development and evolution of three-dimensional visualization technology. It is an interactive multi-source information fusion of three-dimensional dynamic visual system simulation, using computers to create and experience the virtual world, so that users immerse in the interactive environment.

\section{Three-Dimensional Visualization Technology}

The application of three-dimensional visualization technology in engineering construction project management mainly includes three-dimensional animation, virtual reality and the combination of the two. Using computer three-dimensional simulation imaging technology, after three steps of pre-planning, animation production and post-synthesis, the principle of real visual restoration or depth of some difficult scenes in the field of professional technology is analyzed to help customers more intuitively display the corresponding technology, engineering, technology and equipment, maximizing the value of current information.

\subsection{D Animation}

Three-dimensional animation is a technology based on computer graphics and image science. Through the computer three-dimensional simulation imaging tech- 
nology, some difficult scenes in the professional field can be restored by real vision or the principle of depth analysis. It can display the corresponding engineering, technology, equipment and tools more intuitively and pertinently. In other words, the process of presenting abstract concepts in concrete form can maximize the value of information. After the completion of the production, the video file can be generated with a simple media player, which has lower requirements for computer hardware and better versatility.

\subsection{Virtual Reality}

Through the interaction between human and computer, the computer or feedback the information of space scene is in real time. Users can walk along their own route according to their needs. The computer will generate corresponding scenes, and can read some information in the scene by preset, which is highly interactive. It gives users more participation and freedom, but real-time computing and rendering have certain hardware requirements for the device.

\subsection{Combination of 3D Animation and Virtual Reality}

The whole scene is presented in the form of virtual reality, in which users can walk freely, observe and read the information of interest. Among them, we need to show the details of the principle and action, use three-dimensional animation, make it well in advance, load it in virtual reality, so as to achieve the best viewing effect, and save computer resources to the greatest extent, and enhance the use of experience.

\section{Application of Three-Dimensional Visualization Technology in Project Management of Offshore Platform Construction}

The whole construction process of offshore platform project starts from preliminary research until the formal commissioning, which involves procedures, basic design, detailed design, processing design, acquisition of equipment and materials, construction, shipment, transportation, offshore installation and commissioning. The whole process involves multi-department and multi-type coordination.

Because of the inherent uniqueness and one-off characteristics of the project, and the characteristics of ocean engineering, such as complex technology, high investment and high risk, it is of great significance for investment decision-making and technical and managerial personnel to realize the visual display and virtual roaming of expected results before the start of the project construction. The application of three-dimensional visualization technology can display the collected abstract data into visualized images through calculation, processing and synthesis. It can help users realize their ideas intuitively. Visualization is only the display method of the results, and can help improve the management level. 


\subsection{Communication Applications}

The human left brain is responsible for the functions of words and language, while the right brain is responsible for the functions of space, image memory, image and so on. The speed of the right brain is much faster than that of the left brain. Therefore, the acquisition speed of various kinds of information is different, which can be sorted simply as: pure text $<$ picture $<$ three-dimensional image. Therefore, when using intuitive, accurate and visual three-dimensional images to communicate, the efficiency and accuracy are much higher than that of pure text or two-dimensional engineering drawings.

\subsection{Application of Assisted Construction Plan Management}

In the process of virtual reality production, based on the construction plan, design drawings and 3D model of Engineering facilities, the construction time plan is loaded, the construction process is simulated dynamically, and the project plan management is assisted. The time bar element is added to the top of the picture. The time unit is accurate to the sky. The progress in the picture matches the construction plan strictly. As long as we know the construction degree of reality and compare the progress of virtual reality, we can assist the construction plan management.

\subsection{Auxiliary Analysis of Construction Feasibility}

Offshore platforms need to install a large number of special equipment, and many equipment need to be customized and shipped from manufacturers, so the arrival time of equipment leads to many uncertainties. Visualization technology uses accurate size and installation information to produce, can simulate the real installation process of equipment, analyze whether the installation sequence of equipment can be adjusted, interference in the installation process, and the safety of pipeline instrument. It can optimize the construction process to the greatest extent and avoid engineering delays or rework workload.

\subsection{Auxiliary Resource Allocation}

According to the whole project site space, the project scale, manpower, equipment and machinery allocation under construction within the whole site, these resources can be visually displayed, and resource allocation can be intuitively carried out to achieve optimal allocation.

\subsection{Supporting Project Demonstration and Publicity}

Using three-dimensional visualization technology, the expected results of construction projects can be visually displayed, including platform, internal structure of jacket, accurate location and information of equipment, construction standard process, etc.

Dynamic display: It can show the whole process of land construction and offshore installation of offshore platform in an all-round way. With the drag of 
time line, it can check the construction progress of different nodes. Such as drawings, three-dimensional imaging, multi-angle viewing, a large number of planar materials can be combined with dynamic interpretation, employment training and publicity.

A combination of various ways of display: can be realistic, abstract, bird's-eye view, can also be micro, so that people who have not been to the scene to understand the working conditions of the scene, so that the details of the facility scene jump in the picture, real restore.

Interactive display: users can choose viewing angle, time node and viewing time independently. According to their own needs, 360 degrees viewing can be done on, below, left, right, front and back of facilities completed or under construction in the whole site. You can view the device you are interested in, and inquire for detailed information.

\subsection{Application of Training}

Training can use different presentation methods according to different target groups. For the new engineers of the project team, in order to quickly understand the background and general situation of the whole project team, they can watch the whole construction process by watching the project background animation and entering the virtual reality; for the different professional engineers in the same industry, in order to make them deeply understand the construction process and specifications, and the relevant professional interface, they can. Enter the virtual reality, view a process flow pertinently; other relevant personnel, in order to understand the project background and the overall progress of the project, can view the project background animation, build and install animation.

\section{Application Effect of Three-Dimensional Visualization Technology in Offshore Platform Construction Project}

\subsection{Project Description}

The main objects of offshore platform construction and installation are jacket, block, living building, drilling and workover equipment, etc. The construction period and construction technology vary greatly according to the complexity of the platform and the use requirements. Each step in the construction process is subdivided into more basic work. Taking the land construction of blocks as an example, it can be roughly divided into material pretreatment, pipe making, main structure prefabrication and installation, accessories prefabrication and installation, piping, painting, telecommunications, land debugging, weighing and so on.

The whole construction time is short and the workload is heavy. In order to assist the project management and improve the efficiency of communication and management, the project has produced a visual three-dimensional simulation of the whole process of construction and installation, using the combination of virtual reality and three-dimensional animation. The terrestrial construction part of the platform uses virtual reality, which is more interactive for under- 
standing the construction progress, equipment installation, site conditions, etc. The offshore installation and project background parts use three-dimensional animation to watch more targeted and smooth.

\subsection{Functions Implemented}

Integrating the project background, jacket, block construction and installation animation and pre-brake drawing into the virtual reality system, designing the whole interactive interface, you can directly select the items you want to see in the main menu and quickly enter the corresponding interface; after entering the virtual reality interface, you can set up the operation method and function distribution. In the process of using virtual reality, the setting button can call up the setting options, and the corresponding configuration can be selected according to the hardware condition of the computer at any time.

"Jacket Construction and Installation" directly plays three-dimensional animation of the whole process of jacket construction and installation, and briefly introduces the whole process of jacket construction and installation. The process of jacket construction and installation includes the prefabrication and spraying of X-shaped and horizontal pieces of jacket, integral assembly on land, installation of accessories, shipment and transportation, and installation at sea.

"Block Construction and Installation" can directly view the whole process of block construction and installation of three-dimensional animation. The main process of block construction and installation includes: prefabricated spraying, structure hoisting, equipment installation, piping, outfitting, shipment, towing, offshore installation, connection and debugging.

The sub-menus of "Pre-brake Painting" include "Roll Pipe Animation", "Longitudinal Seam Welding", "Circumferential Seam Welding”, "Jacket Painting" and "Deck Painting". Although these animations have been edited as a whole in the corresponding positions of jacket and block animations, they are listed separately here, because they belong to the prefabricated part of materials, have the need to view and study separately, and can be used as training for project team members.

The "Building Virtual Reality" option enters the virtual reality of the construction process of jackets and blocks, displaying the land construction of jackets and blocks in an all-round way. By adding a time progress bar above the screen, you can directly drag to the corresponding date to see the construction progress of different nodes. Users can choose to roam freely and view 360 degrees in completed or under construction facilities throughout the site according to their needs.

During the user's roaming process, you can click on the equipment to see its name and size, or choose the pre-set route to visit the jacket, block prefabrication and installation process.

\subsection{Follow-Up Improvement and Optimization}

Through the exploration and application of this project, some experiences are 
found and summarized, which can improve the efficiency of similar projects in the follow-up.

\subsubsection{Establishment of Model and Material Library}

Many profiles, decks, parts of equipment and pipeline models and materials used on offshore platforms are universal. These models and materials can be collected and sorted out to establish models and materials library, which can be directly modified and used in the production of similar projects, saving production costs and improving production efficiency.

\subsubsection{Modularization}

Some functions implemented in this project, such as timeline control progress function, import and display device name and size function, roaming and viewing function, can be classified and modularized to facilitate reference and modification when similar needs arise.

\subsubsection{Visual Intervention Time in Advance}

The sooner the visualization work is prepared, the more basic work can be completed in the first time, such as model building, scene design, scheme making, etc. It can be put into use earlier and play a wider application value.

\section{Conclusions}

In the practice of practical projects, the visualization results of land construction and offshore installation are made according to the precise model completed by detailed drawings, which greatly improves the communication efficiency of the project and facilitates the reporting and review work; the visualization and visual comparison of actual progress and planned progress is supported by the function of time line, and the progress of the project is assisted by the visualization and visual comparison of actual progress and planned progress. Management: All the results are integrated into the virtual reality, and can also play three-dimensional animation directly to complete the visual display of the expected results of the project; distinguishing different display modes for different purposes can be used as the visual media of project communication, project propaganda and results experience, as well as training, visualization tutorial.

To some extent, the visualization application of engineering construction can replace some traditional forms such as text reports, which can provide intuitive, flexible and strong realistic experience for project management. With the improvement of computing hardware, the accuracy of data and model in three-dimensional visualization can be refined to a greater extent, and better interaction can be generated when connected to parallel databases and external hardware. On this basis, it can also develop online synchronization functions, real-time analysis of the situation, allocation of resources, improve project communication and management efficiency, and develop it into a visual support system covering the whole construction process. 


\section{Conflicts of Interest}

The authors declare no conflicts of interest regarding the publication of this paper.

\section{References}

[1] Wang, W.Z. (2007) Visual Engineering Construction Management. Science and Management, 27, $3 \mathrm{X}$.

[2] Xu, M.C. (2012) Brief Discussion on the Development and Application of ThreeDimensional Visualization at Home and Abroad. Modern Surveying and Mapping, 35, 60-62.

[3] Zhang, J.P., Han, B., Li, J.L. and Lu, W. (2006) 4D Visual Management of Construction Site. Construction Technology, 10, 36-38.

[4] Xia, S.L. (2015) Purchasing Characteristics and Progress Control of Offshore Petroleum Engineering Construction Project. Project Management Technology, 10, 104 108.

[5] Zhang, Lei. (2012) Research on Three-Dimensional System of Oil Depot, Gas Station and Pipeline Operation Training and Virtual Drilling. Oil Depot and Gas Station, 4, 32-36.

[6] Huang, K., Song, H.H., Liu, S., Lin, H. and Wang, Y. (2012) Discussion on the Construction of Digital Oil Depots. Natural Gas and Oil, 1, 96-100.

[7] Wang, J.Y., Zhang, X., Wang, Y. Zhao, and Y.H. (2010) The Development Status, Policies and Enlightenment of Virtual Reality Technology in the United States to China. Science and Technology Management Research, 14, 45-48.

[8] Dang, Q. (2008) Research on 3D Visualization Technology Based on GIS and Its Implementation Method.

[9] Zhang, K.Q. (2006) Research and Implementation of Fire Plan Simulation System Based on Virtual Reality.

[10] Zhang, F.X. (2010) Hazard Identification and Risk Assessment of In-Service Devices in Refining and Chemical Enterprises. Petrochemical Safety and Environmental Protection Technology, 2, 25-28. 